\title{
Alliance of Support for Low-Income Latino Men with Prostate Cancer: God, Doctor, and Self
}

\author{
Sally L. Maliski • Majid Husain • Sarah E. Connor • \\ Mark S. Litwin
}

Published online: 13 July 2010

(C) The Author(s) 2010. This article is published with open access at Springerlink.com

\begin{abstract}
Utilizing qualitative methods, this study describes the perceptions of and reliance on spirituality among indigent Latino men with prostate cancer. Sixty men were interviewed in Spanish. Transcripts were transcribed verbatim, translated, and analyzed using grounded theory techniques. Common across all men was a process involving the formation of an alliance of support that included God, doctors, and self. From this alliance, men drew strength to manage their disease, maintained hope for the future, and found new existential meaning. By recognizing the potential value of this alliance, health care professionals may tap into a beneficial empowering resource for some Latino men.
\end{abstract}

Keywords Prostate cancer $\cdot$ Underserved $\cdot$ Spirituality $\cdot$ Latino

\section{Introduction}

Men, almost universally, consider the diagnosis of prostate cancer to be a death sentence (Maliski et al. 2002, 2008). Next to skin cancer, prostate cancer is the most common solid malignancy among American men, and Latinos are the fastest growing minority in the United States (ACS 2008). Its treatments may have a number of side effects, such as erectile dysfunction, urinary incontinence, bowel dysfunction, fatigue, depression, and hot

\section{S. L. Maliski (西)}

School of Nursing, University of California, Los Angeles (UCLA), 2-256 Factor Bldg, BOX 956918, Los Angeles, CA 90095-6918, USA

e-mail: smaliski@sonnet.ucla.edu

\section{Husain}

University of California, Los Angeles, CA, USA

\section{S. E. Connor}

Department of Urology, University of California, Los Angeles, CA, USA

M. S. Litwin

David Geffen School of Medicine and School of Public Health, University of California, Los Angeles, CA, USA 
flashes; these may be temporary or long-term. Incorporating the disease, its treatments, and side effects into one's life is a complex, multi-faceted process that is important to quality of life.

Studies have shown that spirituality is a tool used by many to make meaning of and cope with disease, its management, and its symptoms (Harvey and Silverman 2007; Walton and Sullivan 2004). In the health care arena, spirituality has been associated with hope, better management of chronic illness, higher levels of health-promoting activities, and better health-related quality of life (HRQOL) (Harvey and Silverman 2007; Klonoff and Landrine 1996; Krause and Van Tran 1989; Waite et al. 1999). Some studies differentiate between religiosity and meaning when referring to spirituality, while others do not.

In one of few studies that considered spirituality among underserved men with prostate cancer, Krupski and colleagues (2006) found that the psychosocial domains of both general and prostate-specific HRQOL were negatively associated with low spirituality among a low-income, uninsured, ethnically diverse group of men treated for prostate cancer. A second study, sampling from the same population, found that the meaning/peace subscale of Functional Assessment of Chronic Illness Therapies-Spirituality (FACIT-Sp) was the major contributor to the positive association between spirituality and HRQOL (Zavala et al. 2009). Furthermore, these investigators found that, in the absence of high meaning/ peace scores, higher faith scores were negatively associated with HRQOL (Zavala et al. 2009). Finally, in a grounded theory study of spirituality among men with prostate cancer, investigators found that spirituality was integral to coping with cancer at all phases: facing cancer, choosing treatment, trusting, and living day by day (Walton and Sullivan 2004). Subjects in the first two studies were from the same population as the current study; those in the third study were all English-speaking with interviews occurring in the hospital during recovery from surgery and no information participant's socioeconomic status or ethnicity was provided. Thus, little is available in the literature to address how low-income, uninsured men, specifically Latinos, may use spirituality to cope with prostate cancer, its treatment, and side effects. Therefore, the purpose of this study was to understand the perception of spirituality in dealing with treatment-related side effects among low-income, uninsured Latino men treated for prostate cancer.

\section{Methods}

A qualitative design was employed. Grounded theory techniques (Strauss and Corbin 1998) were used to develop descriptive categories as they emerged from the data to construct the perception and role of spirituality within the context of having prostate cancer.

\section{Participants and Setting}

The majority ( $n=58$ ) of the men spoke primarily Spanish. Ages ranged from 50 to 65 . Of the 60 Latino men, only two were born in the United States. Only 16 had a high school education or higher. Totally $72 \%$ reported having a partner. Another $11 \%$ reported being in a significant relationship, but not living with a partner. The remaining $17 \%$ reported that they did not currently have a significant relationship. Specific religious affiliation was not queried.

Clinically, $18 \%$ of these Latino men had radiation therapy, and $67 \%$ had surgery as their primary treatment. At the time of the initial interview, $15 \%$ were receiving hormone ablation therapy for biochemical recurrence following primary treatment. Almost half 
$(n=29)$ were being treated or had been out of treatment for less than a year, while 14 of the men had been out of treatment for one to two years. The remaining 17 Latino men had been out of treatment for over 2 years. All men were experiencing or had experienced ED and/or urinary incontinence.

\section{Data Collection}

After receiving human subjects' approval from the University of California, Los Angeles (UCLA) Office for the Protection of Research Subjects, the men who self-reported as Latino were recruited from IMPACT (Improving Access, Counseling, and Treatment for Californians with prostate cancer), a state-funded public health program that provides free prostate cancer treatment and nurse case management to uninsured men with incomes under $200 \%$ of the Federal Poverty Level.

After providing informed consent, the men in our study were scheduled for an initial interview. They were given a choice of having the interview conducted in-person at UCLA, in their home, or by telephone. Telephone was the only option for those living more than 50 miles from UCLA. No differences in information between those interviewed in-person and those interviewed via telephone were observed. The major limitation with telephone interviews was the absence of visual data. Interviewers completed a debriefing form following each interview, on which they noted their impressions of body language and environment for in-person interviews and voice tone and background noise for telephone interviews. All interviews were conducted by a language-concordant, trained male interviewer using a semi-structured interview guide. The interviews lasted one to $2 \mathrm{~h}$ and were opened by asking participants to talk about their treatment and treatment-related symptom experiences starting with learning about having prostate cancer, through treatment, to the present. Although men were not specifically asked about spirituality, references to spiritual issues arose spontaneously.

All the men were contacted for second interviews six to twelve months following their initial interview to clarify or expand on concepts identified in their initial interviews or to confirm emerging themes. Because of the emergent themes related to spirituality, questions related to this area were added to follow-up interview guides. All interviews were transcribed verbatim, translated, back-translated, and verified by two bilingual interpreters to produce English transcripts for analysis (Lopez et al. 2008).

Analysis

Grounded theory (Strauss and Corbin 1998) techniques were used to develop a descriptive model of spirituality among low-income Latino men with prostate cancer. Initially, transcripts were read in their entirety. Next, line-by-line coding was conducted with constant comparison of codes. As coding and comparison continued, common characteristics began to emerge and were used as categories. Concurrently with this process, relational statements were suggested and explored. After relationships were confirmed by the team as supported by the data, the categories were developed to describe antecedents, process, and outcomes related to spirituality. The principal investigator and two members of the study staff independently carried out this interpretive process. Categories and relationships were confirmed by returning to the transcripts and in follow-up interviews. Throughout the analytic process, memos were written on codes and categories as they were developed on decisions about categorization, descriptions of the categories, theoretical hunches and questions, and decisions made about relationships. 


\section{Results}

From this analysis, it became evident that spirituality played a varied but integral role in the lives of these men with prostate cancer. Spirituality manifests as faith and trust in the men's stories. The major commonality across transcripts was a process that involved the formation of an alliance of support. This alliance included God, doctors, and self and was preceded by the diagnosis, which increased their awareness of their own mortality. From this alliance of support, the men drew strength to manage the disease and its effects, maintained hope for the future, and found new existential meaning (Fig. 1).

\section{Antecedents}

\section{Temporality of Life}

The men expressed that they became more aware of their mortality with their diagnosis. This created worry and apprehension. In response, the men talked of experiencing restlessness and uncertainty about life and death. One man described his diagnosis as being torturous and unlike anything he had experienced before. Thus, he felt as if he was being given his own death sentence.

It hit me like cold water... the scare took me like a week (to recover)... I would struggle to sleep... never in my life had I had something so...um...should I say that caused me so much fright that it shook me like that ...it was torture for me.

Participants reported waking in the middle of the night thinking about their "remaining life." One man stated that he was unable to sleep for two to three weeks because he was preoccupied with such thoughts.

Men who had thought they would live well into their 80s and 90s now hoped they would live past 60 . In many cases, one of the first questions the men reported asking was related

\begin{tabular}{|c|c|c|c|}
\hline Antecedents & Outcomes \\
Diagnosis of prostate cancer \\
Handing control to God
\end{tabular}

Fig. 1 Antecedents and outcomes of alliance of support 
to their life expectancy. One man in particular expressed the fear of dying from recurrence if he survived primary treatment. They expressed being more aware of the temporality of life.

I still have in mind that from one moment to another it's going to show up and that from there I'm going (to die).

It's funny to know one's longevity and to know that one is going to die.

\section{Handing Control to God}

Added to their thoughts of death, the men talked of losing control over life and time of death. For two men, this led to suicidal thoughts. However, both decided against suicide by relying on their faith to deal with their situations.

The men also expressed that because God decided their time of death, giving control of fate to God allowed them to concentrate on aspects of the situation that they could control. It also gave them a sense of "calmness." This sense of God's having control led to the formation of an alliance of support.

"And thank God I, I've been taking this illness calmly and now no longer waiting until God wills, when He says this is it, this is it."

\section{Process}

Alliance of Support: God, Doctors, and Self

The men described a joint effort between God, their doctors, and themselves that provided the confidence they needed to deal with prostate cancer. They trusted that this team would overcome their cancer.

Doing My Part: Trusting and Having Faith and Accepting

As part of this alliance, the men verbalized that trusting and having faith were important to their role in dealing with their prostate cancer. They also expressed that they worked with their physician and took responsibility for doing their part to recover and remain healthy.

Some felt that their faith remained stable; others experienced strengthening of their faith. One participant pointed out that prior to his prostate cancer diagnosis, he had forgotten about God, but his diagnosis rekindled his faith. Another reported a similar renewal of faith. For these men, prostate cancer either renewed or reinforced their spiritual beliefs.

I thought well let it be God's will and whatever comes up I'll make the effort to do what can be done well.

It has greatly changed my relationship with God.

Now I have ... to be spiritual with God and not before ... it has changed for me.

This trust and faith calmed many of the men, provided control, and gave them a positive outlook on their treatment and life. It served to strengthen their will to recover and live. Faith also helped the men deal with side effects of their treatments. They had faith that if God willed it, erectile dysfunction and urinary incontinence would resolve. If they did not, they would accept it as the will of God. 
I didn't think about the consequence or anything but I said well what I'm going to do is put it in God's hands.

The men talked of accepting the side effects and adapting to their erectile dysfunction or urinary incontinence using their faith to have the needed strength. Men expressed that life was more valuable than sex and that living with side effects outweighed death. Many men felt that their youth had passed and acting macho was not of importance. While many were optimistic for eventual recovery of function, some were willing to accept their fate, whether good or bad. Still others accepted the illness as a part of their life. These forms of acceptance made it easier for the men to accept their diagnosis and side effects and to move on.

There are times you can resolve it, but there are times that you can't anymore. So then one has to be conscious of all those things.

Faith provided a feeling of control for these men. One man stated that his faith allowed him to deal with suicidal thoughts as well as his pain, because he accepted God's will absolutely. The men also believed that God guided them to the IMPACT program. They felt their trust and faith in God had carried them from life before prostate cancer to post prostate cancer treatment and helped them overcome obstacles throughout.

One is never lonely or helpless if God is by their side and God is constantly providing him with hope and the ability to deal with problems.

Faith allowed the men to accept their situation, when symptoms were long term. Faith was used to reprioritize values and to see the positive outcomes even in the presence of symptoms.

Everyday I... um... I pray and ask God for my health and that He gives me patience to be able to overcome what I feel or that He gives me the ability to take it with patience, to not lose hope that not to feel bad.

The men also recognized that accepting their diagnosis was part of dealing with it. Participants expressed that worrying about their condition was not constructive to their recovery. Rather, accepting that they had cancer and working with their doctors and God was the only way of overcoming prostate cancer. Faith was used to facilitate this acceptance. They expressed that becoming more self-aware of their own mortality had led them to reexamine their values and to become more active in promoting their own health.

The men felt it was their responsibility to take the necessary steps to ensure their own recovery. In fact, one participant stated that as a man, the designated head and spiritual leader of the household, it was his responsibility to undertake the challenge of overcoming prostate cancer. With the guidance of God, he would fulfill his role and the duties designated by God, thereby proving himself a worthy role model for his family. By accepting God's control of their fate, the men could focus their attention on maintaining their health, which they could control.

\section{Treatment: God's Hand and Doctors' Skill}

Trust was especially important as the men underwent treatment. Many participants felt that it was God who had led them to IMPACT and gave the doctors the necessary skills to treat them. They entrusted their lives into the hands of God and their doctors. One participant even called his IMPACT nurse a "guardian angel." Another man stated that God was going to "cure" him. Others felt that God had-through the doctor's skill—given them 
another chance to live. One participant stated the doctors gave him his life back. Moreover, the men felt that God had guided their path to recovery and given them a positive outlook on their treatment and life in general. Placing their fate in God's hands helped the men place trust in the doctors' abilities and strengthened their will to recover.

Then I knew that if they prayed God was going to guide the surgeon's hand.

He connected me with you all (IMPACT). In a way that all of my steps, the function of my life and all that was guided by what is up there.

\section{Outcomes}

Having Gratitude for the "Gift of Life" and Hope for the Future

With a strong sense of faith came a strong sense of hope and gratitude. Participants expressed that "something good was bound to happen." This hope helped the men stay optimistic about the outcome of their treatment. Even though they believed the outcome was up to God, they hoped that God would help them overcome problems. Their expressed hope for a better tomorrow was attributed to their faith. Regardless of the outcome of their treatment and whether or not they suffered from treatment side effects, hope gave the men the feeling that they would have a future.

Many who had been submerged in thoughts of death found strength to change their outlook on life. A few men used their sense of mortality to set new personal goals for themselves.

I am a person with a vision determined to fight death.

Regardless of his short prognosis, one man was determined to live another 10-15 years. Others sought to ensure their families would be economically stable.

I still have 10, 15 years left perhaps so as to have them be successful and with this problem.

Thanks to my beliefs and my faith, to my religion...I've kept going.

God helps us for the future.

Having turned to faith for support and strength, these men expressed gratitude toward God, not only for the treatment but also for continued life. Participants stated that being diagnosed with a life-threatening disease caused them to be more appreciative of their life and compelled them to reflect on themselves and their lives. With this came gratitude and a realignment of priorities. One man stated that God gave him the opportunity to see more and to love others. The men expressed a stronger purpose in life because they felt God had given them the chance to be more useful in the world. Although these men were aware of their mortality, they felt that God had granted them the "gift of life."

I said thank God we've made it like I said we're living overtime.

I can't demand much now from God, nor life, nor me, nor anyone. I think that I found it in time; that was a miracle from God's will. [It] is going to be done right.

\section{Finding New Meaning}

Faith gave meaning and direction to these men's lives as they told their stories. One stated that faith was as much a part of his life as the physical and sexual aspects. Another 


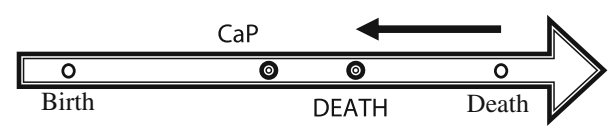

Fig. 2 Participant's post-prostate cancer diagnosis perception of their life span

highlighted that if one is going to "build a life," one needed to look deeper. For him, faith provided that depth of meaning.

The men expressed that spirituality gave them goals such as "to love, reproduce, and to do things in life." They believed that if one believes and makes the effort, one can achieve anything.

Especially in times of hardship, such as prostate cancer, people turn to faith to provide answers. The men in our study were no exception. Many wondered why they were the ones diagnosed with prostate cancer and were unable to answer these questions themselves. They thought about their remaining life because they perceived prostate cancer as a lifethreatening disease. Their faith was used to guide their thoughts and actions and construct new meaning that incorporated the prostate cancer experience. Spirituality not only added meaning and depth to their lives but also put prostate cancer in perspective. It helped them see this as an obstacle or challenge to be overcome in life, as opposed to something to which they must surrender. The aims and goals, which faith provided, helped them conquer their fears of death and accept their prostate cancer. Faith provided them with a source of strength and optimism to recover from cancer (Fig. 2).

\section{Discussion}

Faith is a multi-faceted concept that permeates both the biological and psychological aspects of the lives of the men in our study who were challenged to deal with prostate cancer. Spirituality, as seen in the men's stories, was expressed as faith and trust. Their experience of God, though not mediated by a specific religion or practice, appeared as the men talked of their cancer experience. Formation of an alliance of support, which was a major finding of the study, sheds new light on the positive use of faith by low-income, Latino men in dealing with prostate cancer and its consequences.

This finding was expected considering similar studies that have found a positive correlation between spirituality and HRQOL in men dealing with prostate cancer. However, this has previously not been explored among Latino men. Because spirituality is considered to be one of the important dimensions of health (Coyle 2002; Narayanasamy 2004; Walton and Sullivan 2004; Zavala et al. 2009), it is not surprising that spirituality is a core domain when assessing the HRQOL of patients (Brady et al. 1999). The use of this biopsychosocialspriritual model for HRQOL measurement has provided a unique perspective on how men cope with the prostate cancer diagnosis and the trajectory of this illness. A related quantitative study, assessing the influence of spirituality on the HRQOL of life in men with prostate cancer, showed that an increase in spirituality resulted in an improved HRQOL; that is, more spiritual men experienced greater well-being (Krupski et al. 2006). A few of the themes that emerged in our study (e.g., accepting prostate cancer in a positive and constructive way, perceiving God's hand in treatment, remaining hopeful, and being determined to overcome cancer with the help and support of God) qualitatively compliment the findings of the aforementioned study. In other studies, men dealing with prostate cancer describe how their spirituality provides strength, comfort, and peace in dealing with this illness (Albaugh 2003; Walton and Sullivan 2004). 
The positive influences of spirituality have been found across other diseases, further validating the results of our study. Levine and Targ (2002) found correlations between spirituality and better functional and physical well-being in women with breast cancer (Levine and Targ 2002). Additionally, non-spiritual patients (determined by low FACITSp scores) with chronic diseases report significantly worse quality of life (Riley et al. 1998). Furthermore, a few studies have established a physiological link between spirituality and biological pathways. For instance, Ironson and colleagues (2002) found that greater spirituality associated with longer survival among people with HIV/AIDS was mediated by cortisol (Ironson et al. 2002). Also a higher number of circulating helper and cytotoxic $\mathrm{T}$ cells were found in women with metastatic breast cancer who reported greater spirituality (Sephton et al. 2001).

Another theme that emerged from our research was the temporality of life and the subsequent heightened awareness of mortality. For the men in this study, being diagnosed with prostate cancer undoubtedly evoked concerns about life and death. As a result, many men sought spiritual meaning in their illness to come to terms with their diagnosis. Thomas and Retsas (1999) named this process of developing a spiritual perspective to strengthen their approach toward life and death, "transacting self-preservation" (Thomas and Retsas 1999). It consisted of "taking it all in," "getting on with things," and "putting it all together." Understanding self through this spiritual growth was a way of overcoming barriers and discovering a meaningful experience when facing death. In other studies, drawing meaning from cancer enabled breast cancer survivors to reframe their illness in a more optimistic life (Gibson and Parker 2003; Johnson 2002; Levine and Targ 2002; Sehlen et al. 2003), and men dealing with prostate cancer reframed the perception of their cancer diagnosis from a death sentence to 'good cancer' (Maliski et al. 2002). For the men in our study, faith was an empowering resource that enabled them to take an active role in their treatment and recovery process. In many cases, the men's doctors religious leaders served as the intermediary that modulated this relationship. Men in our study believed that God worked through the hands of the doctors and was responsible for their well-being (Mansfield et al. 2002).

The alliance of support construct is a novel observation in low-income, Latino men. Given the demographic composition of our participants, other factors, such as ethnicity and the socioeconomic status, may be contributing to this seemingly heightened sense of spirituality among Latino men dealing with prostate cancer. Among those factors, Krupski et al. (2006) found that spirituality and ethnicity independently affect HRQOL. But the effects of socioeconomic status on spirituality cannot easily be determined: minorities generally have higher poverty rates, and disentangling the effects of socioeconomic status, ethnicity, and spirituality is difficult. Regardless of these variations, substantial research has provided evidence for the positive influences of spirituality on coping with a disease.

The results of this study must be interpreted with caution. Participants were men receiving free prostate cancer treatment and nurse-directed care management through a state-funded program. Therefore, men who do not have this resource may talk about their faith differently. Also, the Latino men in this study were predominantly Roman Catholic, as they revealed in their interviews, and from Mexico. We do not know how spirituality might influence the prostate cancer experience of men of other faiths or nationalities.

Despite these limitations, the findings of our study suggest that consideration of spirituality is warranted in clinical practice. It is likely that taking into consideration the patient's spiritual beliefs and integrating them into the medical treatment process will provide benefit and HRQOL improvement. Recognizing the potential of entering and using the alliance of support with low-income men with prostate cancer allows health care 
professionals to tap into an empowering resource that may be beneficial for some Latino men.

Acknowledgments This research was supported by a grant from Department of Defense Prostate Cancer Research Program, W81XWH-04-1-0117.

Open Access This article is distributed under the terms of the Creative Commons Attribution Noncommercial License which permits any noncommercial use, distribution, and reproduction in any medium, provided the original author(s) and source are credited.

\section{References}

Albaugh, J. A. (2003). Spirituality and life-threatening illness: A phenomenologic study. Oncology Nursing Forum, 30(4), 593-598.

American Cancer Society. (2008). Cancer Facts and Figures. American Cancer Society.

Brady, M. J., Peterman, A. H., Fitchett, G., Mo, M., \& Cella, D. (1999). A case for including spirituality in quality of life measurement in oncology. Psycho-oncology, 8(5), 417-428.

Coyle, J. (2002). Spirituality and health: Towards a framework for exploring the relationship between spirituality and health. Journal of Advanced Nursing, 37(6), 589-597.

Gibson, L. M., \& Parker, V. (2003). Inner resources as predictors of psychological well-being in middleincome African American breast cancer survivors. Cancer Control, 10(5 Suppl), 52-59.

Harvey, I. S., \& Silverman, M. (2007). The role of spirituality in the self-management of chronic illness among older African and Whites. Journal of Cross Cultural Gerontology, 22(2), 205-220.

Ironson, G., Solomon, G. F., Balbin, E. G., O'Cleirigh, C., George, A., Kumar, M., et al. (2002). The Ironson-woods spirituality/religiousness index is associated with long survival, health behaviors, less distress, and low cortisol in people with HIV/AIDS. Annals of Behavioral Medicine, 24(1), 34-48.

Johnson, P. (2002). The use of humor and its influences on spirituality and coping in breast cancer survivors. Oncology Nursing Forum, 29(4), 691-695.

Klonoff, E., \& Landrine, H. (1996). Belief in the healing power of prayer: Prevalence and health correlates for African American women. Western Journal of Black Studies, 20(4), 207-210.

Krause, N., \& Van Tran, T. (1989). Stress and religious involvement among older blacks. Journal of Gerontology, 44(1), S4-S13.

Krupski, T. L., Kwan, L., Fink, A., Sonn, G. A., Maliski, S., \& Litwin, M. S. (2006). Spirituality influences health related quality of life in men with prostate cancer. Psycho-oncology, 15(2), 121-131.

Levine, E. G., \& Targ, E. (2002). Spiritual correlates of functional well-being in women with breast cancer. Integrated Cancer Therapies, 1(2), 166-174.

Lopez, G., Figueroa, M., Connor, S., \& Maliski, S. (2008). Translation in conducting qualitative research with Spanish speakers. Qualitative Health Research, 18(12), 1729-1737.

Maliski, S. L., Heilemann, M. V., \& McCorkle, R. (2002). From "death sentence" to "good cancer": 'Couples' transformation of a prostate cancer diagnosis. Nursing Research, 51(6), 391-397.

Maliski, S., Rivera, S., Connor, S., Lopez, G., \& Litwin, M. (2008). Renegotiating masculine identity after prostate cancer treatment. Qualitative Health Research, 18(12), 1609-1620.

Mansfield, C. J., Mitchell, J., \& King, D. E. (2002). The doctor as God's mechanic? Beliefs in the Southeastern United States. Social Science and Medicine, 54(3), 399-409.

Narayanasamy, A. (2004). The puzzle of spirituality for nursing: A guide to practical assessment. British Journal of Nursing, 13(19), 1140-1144.

Riley, B. B., Perna, R., Tate, D. G., Forchheimer, M., Anderson, C., \& Luera, G. (1998). Types of spiritual well-being among persons with chronic illness: Their relation to various forms of quality of life. Archives of Physical Medicine and Rehabilitation, 79(3), 258-264.

Sehlen, S., Lenk, M., Hollenhorst, H., Schymura, B., Aydemir, U., Herschbach, P., et al. (2003). Quality of life (QoL) as predictive mediator variable for survival in patients with intracerebral neoplasma during radiotherapy. Onkologie, 26(1), 38-43.

Sephton, S. E., Koopman, C., Schaal, M., Thoresen, C., \& Spiegel, D. (2001). Spiritual expression and immune status in women with metastatic breast cancer: An exploratory study. Breast Journal, 7(5), $345-353$.

Strauss, A., \& Corbin, J. (1998). Basics of qualitative research (2nd ed.). Thousand Oaks, CA: Sage Publications. 
Thomas, J., \& Retsas, A. (1999). Transacting self-preservation: A grounded theory of the spiritual dimensions of people with terminal cancer. International Journal of Nursing Studies, 36(3), 191-201.

Waite, P. J., Hawks, S. R., \& Gast, J. A. (1999). The correlation between spiritual well-being and health behaviors. American Journal of Health Promotion, 13(3), 159-162.

Walton, J., \& Sullivan, N. (2004). Men of prayer: spirituality of men with prostate cancer: A grounded theory study. Journal of Holistic Nursing, 22(2), 133-151.

Zavala, M. W., Maliski, S. L., Kwan, L., Fink, A., \& Litwin, M. S. (2009). Spirituality and quality of life in low-income men with metastatic prostate cancer. Psycho-oncology, 18(7), 753-761. 